\section{Adenosindiphosphat-Rezeptoren der Thrombozyten}

\section{T. Stief}

Institut für Laboratoriumsmedizin und Pathobiochemie, Krankenhaus der Philipps-Universität, Marburg, Deutschland

Synonym(e) ADP-Rezeptoren der Blutplättchen

\section{Englischer Begriff platelet ADP receptors}

Definition Rezeptoren für extrazelluläre Nukleotide gehören zur P2-Familie, die aus zwei Rezeptortypen besteht: P2X (,ligand-gated-cation channels“, Kationenkanäle) und P2Y (G-Protein-gekoppelt). > Thrombozyten exprimieren den P2X1-Kationenkanal, der durch ATP (Adenosintriphosphat) reguliert wird, und die P2Y1- und P2Y12-Rezeptoren, die durch ADP aktiviert werden.

Beschreibung ADP in geringen Mengen ist nur ein schwacher Induktor der Thrombozytenaggregation ( $\triangleright$ Thrombozytenaggregation und -aktivierung). Da ADP in großen Mengen aus den Dense Granula der Thrombozyten nach Stimulation freigesetzt wird, amplifiziert ADP als sekundärer Agonist die Reaktion der Thrombozyten auf andere Agonisten der Thrombozytenaggregation. ADP stabilisiert somit Thrombozytenaggregate. ADP bindet an P2Y1, das über das G-Protein $\alpha q$ intrazelluläre Calcium-Ionen mobilisiert. Dies verändert die Thrombozyten-Morphologie („shape change“) und bewirkt eine schwache reversible Aggregation. Die Blockierung dieses Rezeptors führt zum kompletten Verlust der Aggregabilität der Thrombozyten und zum Ausbleiben des "shape change“. Der P2Y12-Rezeptor vermittelt über G-Protein Gai2 die Hemmung der Adenylatcyclase (AC; d. h. Hemmung der Produktion an zyklischem Adenosinmonophosphat [cAMP]). P2Y12 ist das pharmakologische Ziel der irreversiblen Thrombozyteninhibitoren Clopidogrel und Prasugrel als auch der kompetitiven Antagonisten Cangrelor und AZD6140. Blockade des P2Y12-Rezeptors führt zu einer starken Inhibition der Aggregation (mit schwachen oder mittelstarken Induktoren).

Die Funktionalität beider Rezeptoren ist notwendig für eine normale ADP-vermittelte Stimulation der Thrombozyten. Aktivierung von P2Y12 führt auch zu einer Exposition von Phosphatidylserin (,flip-flop“ der Membranphospholipide [PL], d. h. Innen-PL werden zu Außen-PL) an die Thrombozytenoberfläche, wodurch eine prokoagulatorische Matrix entsteht.

\section{Literatur}

Gachet C (2008) P2 receptors, platelet function and pharmacological implications. Thromb Haemost 99:466-472 